\title{
Chapter 19 \\ Identity at the Crossroads, Collision or Conciliation? A Commentary
}

\author{
Einat Heyd-Metzuyanim
}

\subsection{Synthesizing the Four Chapters on Identity and Teachers' Beliefs}

The four chapters in this book that have been collected under the term "identity" span a wide variety of empirical domains, theoretical frameworks and methodologies. In this commentary, I will first attempt to synthesize what can be learned from each of the chapters on its own, and what message can be taken from them as a whole. To do this, I will use my own discursive lens on identity (Heyd-Metzuyanim, 2015; Sfard \& Prusak, 2005), attempting to "translate" the different terminologies and findings into a single conceptual language. I will then examine what the discursive lens that I am proposing highlights about the different studies, including what it exposes that remains hidden or obscure in the chapter, as well as what this lens fails to expose. I will conclude by some meta-remarks about the state of (in)commensurabilities between different approaches to the study of identity in mathematics education.

The empirical domains covered in the four chapters span from teachers' beliefs about mathematics (Erens and Eichler), through their professional identity as teachers (Karaolis and Philippou), the struggle of South African teachers for recognition (Felix) to students identity construction as it interacts with rationality in mathematical group work (Branchetti and Morselli). Theoretical frameworks and underpinnings span from the psychological (Erens \& Eichler; Karaolis and Philippou) to the narrative and sociological (Felix) and the discursive (Branchetti and Morselli). Types of data range from questionnaires (Karaolis and Philippou), to interviews (Karaolis and Philippou, Erens and Eichler, Felix) to observations and transcriptions of classroom talk (Branchetti and Morselli). Analysis ranges from statistical analysis of large number of questionnaires, backed by qualitative analysis of interviews for validation purposes (Karaolis and Philippou), categories analysis of interviews (Erens and Eich-

\footnotetext{
E. Heyd-Metzuyanim ( $\square)$

Tehnion-Israel Institute of Technology, Haifa, Israel

e-mail: einat.metz@gmail.com
} 
ler), narrative analysis of interviews (Felix) and analysis of talk and communication (Brachetti and Morselli).

This wide variability of empirical domains, disciplines and methodologies, and especially the fact that these do not necessarily form into neat packages, signals that identity in mathematics education is a field at the crossroads of various disciplinary approaches. Recently (Heyd-Metzuyanim, 2017), I have claimed "identity" to be a nexus of studies of affect and discourse. The group of identity studies collected in this book shows that it is more than that-it may be thought of as a nexus of studies on the subject (human self) and the study of mathematical activity (including mathematical learning and teaching).

Yet in order for the field of identity to be thought of as a "nexus", and even more practically, for understanding how the four chapters can be synthesized, one has to find a common language to talk about them. On first sight, this seems to be a difficult task. Each of the papers uses the term "identity" differently, and relates with it to different topics. Karaolis and Philoppou define Teacher's Professional Identity (TPI) as "the meanings that people attach to themselves as a result of the interaction among elements of the teacher as a person and as a professional at a given moment". Felix, on the other hand, talks about teachers' professional identities as "continuously being shaped through the processes of becoming members of and participating in the activities of professional communities of practice" adding, in reliance on Sfard and Prusak (2005) that this professional identity is "storied". Branchetti and Morselli also refer to Sfard and Prusak's definition as "Identity as a set of reifying, significant, endorsable stories about a person", yet they talk about students' identities, not teachers', and do not refer to the community in which these students "become participants". Thus it is unclear to what extent their definition agrees with that of Felix. The problem becomes even more complex when one wishes to synthesize the findings of Erens and Eichler, who in fact do not use the term "identity" in their chapter at all. Rather, they use the term "teachers' beliefs" where they define beliefs as "propositions about a certain topic that are individually thought to be true".

On what basis, can we thus even claim that there is a common theme to the chapters, one which can be termed "identity"? This question has important implications to the young field of identity in mathematics education [see recent reviews of work in the field of learners' and teachers' identity by Darragh (2016), Lutovac and Kaasila (2017)]. If we do not know what belongs to the domain of "identity" and what does not, how can we proceed to even claim it is a "field"? How would we, researchers interested in "identity", know with whom we share our interests?

To gain some insight about the common themes and differences between the chapters, there is clearly a need for a common unit of analysis, a sort of conceptual "yardstick" that will enable translation of each of the chapters to one common language. Naturally, I will apply my own conceptual framework, which conceptualizes identity construction as a discursive or communicational activity (Heyd-Metzuyanim, 2015; Sfard \& Prusak, 2005). Yet I wish to stress that by doing this, I am not claiming that my own definition is the definition that should be adopted by all researchers. On the contrary, as I will show later on, this communicational lens has its own drawbacks. 
Yet it is also useful for translating different studies into one common language and for highlighting some interesting commonalities and differences between them.

A communicational lens on identity conceptualizes identity as a collection of narratives about a person. These narratives can be told in the first person (as in "I am a mathematics teacher") or in the third person ("she is a talented mathematics student"). The referee of the stories can be oneself (denoted as ${ }_{\mathrm{A}} \mathrm{A}_{\mathrm{A}}$ stories-stories told about oneself, by oneself, to oneself) or someone else (denoted by ${ }_{A} A_{C}$ : A tells a story about $A$ to $C$ ). They can also be told by a second party to a third party $\left({ }_{B} A_{C}\right)$, in which case the referent has not access to them (for example, when teachers talk about students in pedagogical meetings). Using this lens, one can see that all the chapters in this collection tell stories of this type. Mostly, these are ${ }_{\mathrm{A}} \mathrm{A}_{\mathrm{C}}$ stories, where the research participants tell stories about themselves to the researcher.

Thus, Karolis and Philippou report on their attempt to construct a survey for measuring Teachers Professional Identity (TPI). In communicational terms, this can be seen as developing an instrument that can efficiently collect 1 st $\mathrm{P}$ stories (of the ${ }_{\mathrm{A}} \mathrm{A}_{\mathrm{C}}$ type) of teachers about what Karolis and Philippou term "the answer to the question: 'Who am I as a teacher at this moment'". Of course, these 1st P stories are not as elaborated compared to naturally elicited talk of teachers about themselves. They can be thought of as short "modified versions" of these 1 st P stories, obtained by requesting participants to endorse (or not) certain pre-given narratives through Likertstyle items: narratives constructed by researchers and extracted from many previous narratives of people in similar roles. Given that Karolis and Philippou aim to obtain a general picture of teachers 1st $\mathrm{P}$ stories and commonalities within them, such an abbreviation and standardization of full-scale 1st $\mathrm{P}$ stories is a necessary procedure. They make up for it by obtaining richer and fuller stories through interviews with 20 teachers. Their study yields several interesting results. For example, they report that narratives about one's goals and aspirations as a teacher (motivational aspects), narratives about one's confidence in his/her effectiveness as a teacher (self-efficacy) and narratives about how students are best to be taught (constructivist vs. traditional perceptions) tend to "cluster together". These clustering are sufficiently strong (in statistical terms) to be termed as "types" of teachers' professional identity and to be examined in relation to other characteristics (such as teachers' experience, level of education, etc.).

Felix finds 1st $\mathrm{P}$ stories of teachers in relation to how other colleagues view them-and especially how they evaluate and respect them. His research highlights the relevance of the socio-political sphere in which teachers work and develop their 1st $\mathrm{P}$ stories about themselves. In other words, it brings to the fore the relevance of 3rd P stories about teachers (as told by others or even imagined by the teacher) to the construction of 1st P teachers' stories. Through the highly compelling stories of three teachers with long years of experience, and with widely different racial and social positions in the South African educational sphere, Felix not only exposes the struggles that such teachers encounter, but also the resources of strength and "survival" in such difficult settings.

Turning our gaze to the domain of students' 1st P stories, Branchetti and Morselli attempt to extract such stories of elementary school students about themselves as 
"good" or "bad" in mathematics. They do so by observing and analyzing their mathematical discourse in group activities. Branchetti and Morselli's findings point to interesting relationships between the rationality of students' statements, namely the ways in which students substantiate their mathematical claims (or do not substantiate them) and their communicated identity. They conclude that the existence of two "strong identities" in one group may lead to strong disagreements based on epistemic differences. These disagreements, if not carefully mediated by the teacher, may be prematurely dissolved due to communicational or social goals.

Finally, though Erens and Eichler use the term "teachers' beliefs", their research too deals with teachers' $1 \mathrm{st} \mathrm{P}$ stories, though these stories are interwoven with stories about mathematics, and more precisely, about the teaching and learning of calculus. The fact that their data deals with 1st P stories can be seen in the quotes they bring as example of teachers' beliefs. For example, they quote a teacher (Mrs. M) saying "For an introduction, I would definitely use an example with body growth or population growth. Mainly because these are questions that arouse students' interest and seem to be useful for them." (Erens and Eichler, emphasis added). As indicated by the phrase underlined, the quoted teacher is talking about herself, telling a story about how she would go about teaching a certain subject in calculus. Erens and Eichler's study reveals interesting insights about teachers' 1st $\mathrm{P}$ stories in relation to how they teach calculus (and how they claim it should be taught). For example, they find these narratives to be quite stable and not easily changed, not even by the pre-service program where these teachers have gotten their diploma from. Though they do find indications of teachers appropriating narratives from their educational surrounding, they mostly see teachers holding strongly to narratives that they had endorsed about the teaching and learning of calculus even before they started their training as teachers. Or at least, they find teachers reporting that they had not changed their beliefs during their teacher training process.

\subsection{What Is to Be Gained from a Unified Discursive View on Identity and Beliefs?}

Having translated the different studies of "identity" and "beliefs" according to one conceptual "yardstick", it is time to reflect on what this unified view enables us to see. Following are a few observations:

The gap between identity and mathematics. Though identity may be conceptualized as a nexus between research on affect and research on mathematical activity, the connection, as arising from these four chapters, is far from straightforward. Studies which concentrated mostly on 1st P stories (Felix; Karaolis and Phillipou), hardly dealt with mathematics. They both concentrated on teachers' professional identity, but rarely, if at all, related to these teachers' activity as teaching mathematics. In contrast, the two studies which did deal directly with the teaching of mathematics (Erens and Eichler, Branchetti and Morselli) reported on 1st P narratives only in 
indirect ways. While Erens and Eichler quoted subjects did include 1st P narratives, the authors mostly reported about these as propositions (beliefs) about the mathematics. Branchetti and Morselli, on the other hand, did talk about identities, yet their data rarely included any 1st P statement of the participants about themselves. This is understandable, given that learners rarely talk about themselves while doing mathematics. Thus Branchetti and Morselli attempted to extract the students' 1st P stories as communicated from their mathematical statements. For example, the girl reported in their study as "identifying as 'good in math"” never actually said an utterance similar to "I am good in math". Rather, the researchers assumed that her actions indicated she was telling such a story about herself to herself and to others.

The difference between stories-about-people (subjectifying) and stories about mathematics (mathematizing) is not a simple matter, and I believe that the focus on one side of the divide, at the expense of the other, is not a matter of chance. Studies of identity in particular, and of affect in general, have often found it difficult to connect between the "self" and the mathematics with which this "self" engages. There are several reasons why this gap is so difficult to overcome. One of them is an issue of time-scale. Whereas the time-scale in which identities (stable stories of oneself about oneself) get constructed and changed is often months and years, the timescale in which mathematical activity takes place is seconds and minutes. A result of this difference is a difference in researchers' methods of data collection and analysis. Whereas identity is often studied through interviews or other measures of self-report that can tell a story of a wide time-span (asking people to recount their history as learners, for example), mathematical learning is studied by observations, short interval pre and post-tests and similar measures.

Another, and probably related issue contributing to the gap, are the different theoretical frameworks used historically to examine self and identities versus those used to examine mathematical activity. There is of course wide variability in these theoretical frameworks, yet still, the great amount of research on mathematical learning and teaching is done from a cognitive-psychology perspective, while the research on identities is done either from a social-psychology or sociological and postmodern perspectives. The wide divergence of approaches to identity have made it difficult for the field to converge on findings about identity (Darragh, 2016), let alone to link itself to a field with widely different approaches such as cognitive psychology.

The collapse of 1st P and 3rd P stories in studies of identity. The "conceptual" yardstick of identity as 1st P stories exposes, on a close look, that the "identities", "beliefs" and "self" related constructs are often not exactly the participants' 1st P story but rather the 3rd $\mathrm{P}$ story of the researcher about the participant. In other words, stories of the type Researcher $\mathrm{A}^{\mathrm{A}} \mathrm{A}_{\text {Reader }}$ are collapsed or made indistinct with ${ }_{\mathrm{A}} \mathrm{A}_{\mathrm{A}}$ stories or even ${ }_{\mathrm{A}} \mathrm{A}_{\mathrm{C}}$ stories. The unpacking of the collapse can reveal alternative explanations of the data, which remain hidden behind the collapse and the voice of the researcher. 
Since ${ }_{A} A_{A}$ stories are, by definition, inaccessible to others (unlike ${ }_{A} A_{C}$ stories), one may claim that such a collapse is a necessary compromise that researchers have to make, if they want to say anything about the internal mental state of the person. Also, since bringing stories in their full ${ }_{\mathrm{A}} \mathrm{A}_{\mathrm{C}}$ form (as in quoting from interviews) is highly ineffective, especially if one wants to make a useful condensation of these stories over a large number of participants, one could claim that summarizing ${ }_{\mathrm{A}} \mathrm{A}_{\mathrm{C}}$ into researchers' narratives is inevitable. I do not argue with these claims. Rather, I wish to point to the ubiquity of the collapse between 1st P stories and 3rd P stories in the chapters, so as to exemplify my claims and to examine what is gained or lost from such a collapse.

Collapses between 1st $\mathrm{P}$ and 3rd P stories are so common in the writing on identity and more generally on human psychology that it is difficult to see how one could communicate about the subject without them. Take for example the following passage from Erens and Eichler, where they report on Mrs. U's quote and thereafter interpret it in their own words:

Mrs. U. (TT, 1st): As it is stated here, that's a bit of a danger concerning calculus, that some things are carried out just because it is done like that. The overall picture is missing then, but I have the ambition to teach calculus in encouraging students to try to connect different concepts such as differentiation and integration

This quote is followed by the following report: "In the second interview Mrs. U. confirmed her overarching central goal of a process orientation."

The "overarching central goal of a process orientation" is, of course, the story that Erens and Eichler tell about Mrs. U's goals, not the story she told. Mrs. U talked in terms of "encouraging students to try to connect different concepts". The term "process orientation" is not part of her lexicon (at least as seen in this quote), yet the message communicated by the text is that process orientation is her central goal (namely her 1st P story of her own goals). Thus, there is a collapse here between Mrs. U's 1st P stories and Erens and Eichler stories about her. Yet avoiding this collapse would mean that either Erens and Eichler interject each of their claim with a hedging of the sort "we interpret Mrs. U's beliefs to be of the sort that we term 'process orientation", which would be of course very cumbersome, or giving up analyzing her talk as indicating beliefs altogether. I will tend to the costs of such an abstention in a short while. Before I do that, however, I wish to exemplify the collapse of 1 st $\mathrm{P}$ and 3rd P stories with another short excerpt from the identity chapters, namely that of Felix, describing one of his teacher's feelings:

When P1's colleagues denied his contributions to the school's good pass rates in mathematics and science, "No, it's not your results!", and attempted to undermine him, "All right, I'm going to do a and b and c, and see what he will do!", he experienced their actions as an insult and denigration of his worth as a teacher and self-esteem. 
Here, we see the story of P1 about his colleagues collapsed with the author's story of how P1's colleagues treated him. This can be seen in statements like "When P1's colleagues denied his contributions" which describe P1's colleagues as indeed denying his contributions, not as the story of $P 1$ about his colleagues' denial of his contributions. Notably, this collapse hides alternative interpretations, such as that P1's colleagues said such things but did not intend to undermine him, or that their words and actions were interpreted wrongly (or differently than intended) by P1.

A second type of collapse can be seen in the story of P1's mental experiences collapsed with the author's story of these experiences. For example, when stating "he experienced their actions as an insult." Here, the collapse is between P1's stories of his mental experiences (which, in fact, do not include the word "insult" or any other direct description of an emotional state) and the author's 3rd P story of P1 as being insulted. To clarify how this is different than a discursive description, one just needs to examine the difference between "P1 felt insulted" and "P1 said he felt insulted". While in the first sentence, the researcher presents himself as a direct observer (and reporter) of P1's feelings, in the second, $\mathrm{P} 1$ is the sole observer of his own feelings while the researcher reports on $\mathrm{P} 1 \mathrm{~s}$ description of these feelings. Yet the ubiquity of this collapse in all writings on human feelings and emotions hints that such an unpacking is not such a simple matter. First, because people rarely talk about their mental states or emotions explictly. Thus, it would be rare to find someone like P1 saying "I felt insulted", and unless he used the specific word "insulted", a report of the type "P1 said he felt insulted" would be inaccurate at best. Since people rarely use "emotion words" unless explicitly called for, it is very easy for the researcher, perhaps even necessary, to "fill in" with his own story of these emotional states. A second reason such a collapse is difficult to avoid is that emotional states such as "being insulted" are not fully captured in any descriptive word that the interviewee may have said. To see this, one just needs to imagine P1 saying "I felt insulted because they said X Y Z about me" vs. the story he was quoted saying this. We, as readers can identify in ourselves feelings that we would pair with the word "insulted" better when we read a passage such as that quoted from P1 than from a static verbal description such as "I felt insulted".

Yet despite the ubiquity of the collapse between 1st $\mathrm{P}$ reports about feelings and researchers' reports (3rd P stories) about the subject's feelings, it is important to notice what we lose from this collapse. Most importantly, the collapse hides alternative possibilities to the 3rd P story offered by the researcher of the subject's feelings. For example, it may be that P1, if asked, would not have defined his feelings as exactly "insulted" but rather as "angry" or "resentful". The collapse desensitizes us to such alternative interpretations. It thus makes it easy, for us as readers, to unify our story of P1's feelings with the researchers' story and with P1's story without questioning the possible divergence between these different stories.

For reasons of brevity, I have brought only two examples of such collapses of 1st $\mathrm{P}$ and 3rd P stories, yet they are prevalent in all the chapters, as they are in other writings on identity and on human psychology in general. What should we take from this? One conclusion, which has been prominent in discursive psychology writings (Harré \& Gillett, 1994; Molder, 2015; Potter, 2010) is to avoid concepts referring 
to "inner" mental constructs altogether. The rationale is that such concepts are not only inaccessible to public investigation, they are also fraught with blurry definitions and susceptible, as shown above, to interpretations that do not accurately depict the discourse of the subject who is being studied. Yet what these advocates of abandoning mental constructs often fail to mention is that the usage of mental concepts such as "beliefs", "self" or even "identity" (in its more mentalistic definitions) serves in psychological theories to achieve ends that would be impossible to achieve without these concepts.

Take, for example, Felix's study of self-worth in relation to self-esteem and selfconfidence. Stripping Felix's findings to discursive terms, one may say that teachers' narratives about them being seen as worthy teachers, are found to go hand in hand with their narratives about feeling confident about themselves in more general domains ("self-confidence") and about having received loving and strengthening narratives from significant others when they were young. Such a communicational description is fine, yet it fails to achieve the causative explanation that Felix probably wishes to put forward-that self-worth is built upon self-esteem and that this, in turn, is built upon self-confidence. Without this causative claim, Felix's observations, which lead him to hypothesize about the importance of teachers' psychological stability to the successful endurance with counterproductive narratives around them, lose their explanatory force.

A similar claim can be made about Erens and Eichler's study, where beliefs are construed as objects that cause certain pedagogical actions. There would not be much sense in Erens and Eichler's study of teachers' beliefs, without the objectification of "beliefs" and "behavior" into objects relating to each other in a causal mechanism. After all, Erens and Eichler are probably interested in the teachers' beliefs not per se, but as indicators (or predictors) of teachers' actions in the classroom. So are Karolis and Phillipou, who are probably measuring Teachers' Professional Identity not for the sake of itself, but to be able to predict different profiles of teachers' identity in relation to their education as well as in relation to their conduct in the classroom. Even Branchetti and Morselli, who on the face of it seem to be dealing only with classroom discourse, are focused (though mostly implicitly) on causative explanations for students' actions. They state, for example, their goal to be able to relate between students' identities and the rationality of their arguments. This is not just to be able to describe the situation, but rather to be able to help the teacher to predict in which places "strong identities" and "weak identities" may interfere with successful learning in group situations. One may argue that the discursive lens can also point to causative explanations: those offered by the participants themselves. Yet it seems to me that all the authors of the reviewed chapters wish to do more than that - they wish to offer their own causative explanations for the phenomena they observe. 


\subsection{Conclusions}

The discursive lens that I have employed in this chapter to unify for myself (and the readers) the four chapters that use a variety of terminologies, proves to be useful for being a "conceptual yardstick" a well as illuminating some alternative interpretations of the data that the collapse of 1st P stories and 3rd P stories are bound to hide. Yet it also falls short of providing alternative explanations offered by the authors for their findings.

Why is this important? Since it exemplifies that any theoretical lens has some benefits, and some shortcomings. This revelation is of course as old as the study and theorizing of human activity. Yet being at the crossroads of psychological and discursive perspectives, the field of identity is at a constant danger of being divided by "paradigm wars" (Goldin, 2003). The question we should think about, as a young field, is how do we deal with this danger? Do we aim to conciliate the different paradigms? Do we choose to adhere to their divisions? The lens that I have used, that of discursive psychology, has not been famous for being a "conciliatory" lens. Rather, discursive psychologists have often criticized cognitive and social psychology without necessarily offering alternatives. On the other hand, "conciliatory" approaches have often come from dominant discourses, in which case one can claim that it is easy to call for conciliation from the point of view of the hegemonic discourse. It is a question to our field, how we can preserve the integrity of the approaches, avoiding "theoretical soups" and the usage of incommensurable theories or frameworks, while still benefiting from each of the approaches. The four chapters dealing with identity in this book prove that each of the approaches is valuable and therefore, none of them should be dismissed. How they should talk to each other, however, remains an open question.

\section{References}

Darragh, L. (2016). Identity research in mathematics education. Educational Studies in Mathematics, 93(1), 19-33. https://doi.org/10.1007/s10649-016-9696-5.

Goldin, G. A. (2003). Developing complex understandings: On the relation of mathematics education research to mathematics. Educational Studies in Mathematics, 54, 171-202.

Harré, R., \& Gillett, G. (1994). The discursive mind. Thousand Oaks, CA: Sage Publications.

Heyd-Metzuyanim, E. (2015). Vicious cycles of identifying and mathematizing-A case study of the development of mathematical failure. Journal of the Learning Sciences, 24(4), 504-549.

Heyd-Metzuyanim, E. (2017). Identity as a nexus of affect and discourse in mathematical learning. For the Learning of Mathematics, 37(3), 33-38.

Lutovac, S., \& Kaasila, R. (2017). Future directions in research on mathematics-related teacher identity. International Journal of Science and Mathematics Education, 1-18. https://doi.org/10. 1007/s10763-017-9796-4.

Potter, J. (2010). Contemporary discursive psychology: Issues, prospects, and Corcoran's awkward ontology. British Journal of Social Psychology, 49(4), 657-678. https://doi.org/10.1348/ $014466610 X 486158$. 
Sfard, A., \& Prusak, A. (2005). Telling identities: In search of an analytic tool for investigating learning as a culturally shaped activity. Educational Researcher, 34(4), 14-22.

Te Molder, H. (2015). Discursive psychology. The International Encyclopedia of Language and Social Interaction, 73-90. https://doi.org/10.1348/0261510042378209.

Open Access This chapter is licensed under the terms of the Creative Commons Attribution 4.0 International License (http://creativecommons.org/licenses/by/4.0/), which permits use, sharing, adaptation, distribution and reproduction in any medium or format, as long as you give appropriate credit to the original author(s) and the source, provide a link to the Creative Commons license and indicate if changes were made.

The images or other third party material in this chapter are included in the chapter's Creative Commons license, unless indicated otherwise in a credit line to the material. If material is not included in the chapter's Creative Commons license and your intended use is not permitted by statutory regulation or exceeds the permitted use, you will need to obtain permission directly from the copyright holder.

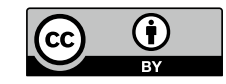

